\title{
RESEARCH
}

\section{The effect of publication on Internet-based solicitation of personal-injury litigants}

\author{
David N. Juurlink MD PhD, Laura Y. Park-Wyllie PharmD MSc, Moira K. Kapral MD MSc
}

\section{ABSTRACT}

Serious adverse drug events can prompt personal-injury lawsuits. However, the extent to which biomedical publication regarding drug-induced harm can influence the legal process has not been well characterized. Using an advanced Google search strategy, we determined the number of Internet "hits" for websites soliciting plaintiffs for medicolegal action before and after publication of a study that highlighted the risk of dysglycemia among patients taking the antibiotic gatifloxacin. We found that early online release and print publication were associated with an immediate and sustained increase in the number of websites soliciting plaintiffs for legal action.

Une version française de ce résumé est disponible à l'adresse www.cmaj.ca/cgi/content/full/I77/II/I369/DCI

CMAJ 2007;I77(II):1369-70

$\mathrm{P}$ ersonal-injury claims for drug-related adverse effects are common, and the resulting monetary awards can be substantial even when cases do not proceed to trial. Highprofile cases often generate a large number of claimants. For example, lawsuits against Merck have increased dramatically following the company's withdrawal of Vioxx. There are more than 30000 pending lawsuits related to this product alone. ${ }^{1}$

The Internet allows potential claimants ready access to personal-injury lawyers, and it allows law firms to easily identify potential claimants. The use of the Internet by lawyers to advertise their services is permissible provided that the communications are not false or misleading. ${ }^{2}$

Biomedical publications can rapidly influence medical practice, ${ }^{3}$ but the extent to which such publications influence litigation is unknown. We studied the extent to which an article published in a general medical journal, along with related events, influenced Internet-based solicitation of plaintiffs for personal-injury litigation.

\section{Methods}

On Mar. I, 2006, the New England Journal of Medicine released ahead-of-print a pharmacoepidemiologic study demonstrating that the antibiotic gatifloxacin (Tequin, Bristol-Myers
Squibb) was strongly associated with the development of hypoglycemia and hyperglycemia among outpatients aged 66 years and older. ${ }^{4}$ This study was released I4 days after the manufacturer and the US Food and Drug Administration jointly strengthened warnings about the drug and 29 days before the article's full publication on Mar. 30, 2006. On May I, 2006, the manufacturer ceased marketing the drug worldwide.

Beginning on the date of acceptance of the manuscript (Feb. 9, 2006), we conducted daily Internet searches for websites offering legal representation to people who had possibly been injured by Tequin. Using the Internet search engine Google, each of the authors determined the number of "hits" each day using a structured search strategy that was piloted and refined in the weeks before the manuscript's acceptance. For the purposes of this study, we defined a "hit" as any website that contributed to the total website count generated using the search strategy, regardless of whether duplicate or highly similar websites were included. The goal of our search was specificity rather than sensitivity.

\section{Search strategy}

We used the advanced search feature provided by Google (available at www.google.ca/advanced_search). We searched for websites that contained all of the search phrases "Tequin," "lawsuit," "lawyer" and "personal injury," and that included any of the words "hypoglycemia," "hyperglycemia," "glucose" or "sugar." We excluded websites that contained "pharmacy" to avoid the identification of online pharmacies. We restricted our search to English-language websites, and we did not impose geographic restrictions.

\section{Results}

Figure I shows the mean number of websites that we identified during the study period. About 20 websites were identified each day during the week following the manuscript's acceptance. This number doubled in the week before the article's early release, presumably as a result of the

From the Department of Medicine and the Clinical Epidemiology Unit, Sunnybrook Health Sciences Centre (Juurlink); the Department of Family and Community Medicine, St. Michael's Hospital (Park-Wyllie); the Department of Medicine and the Clinical Epidemiology Unit, University Health Network (Kapral); and the Institute for Clinical Evaluative Sciences (Juurlink, ParkWyllie, Kapral), Toronto, Ont. 


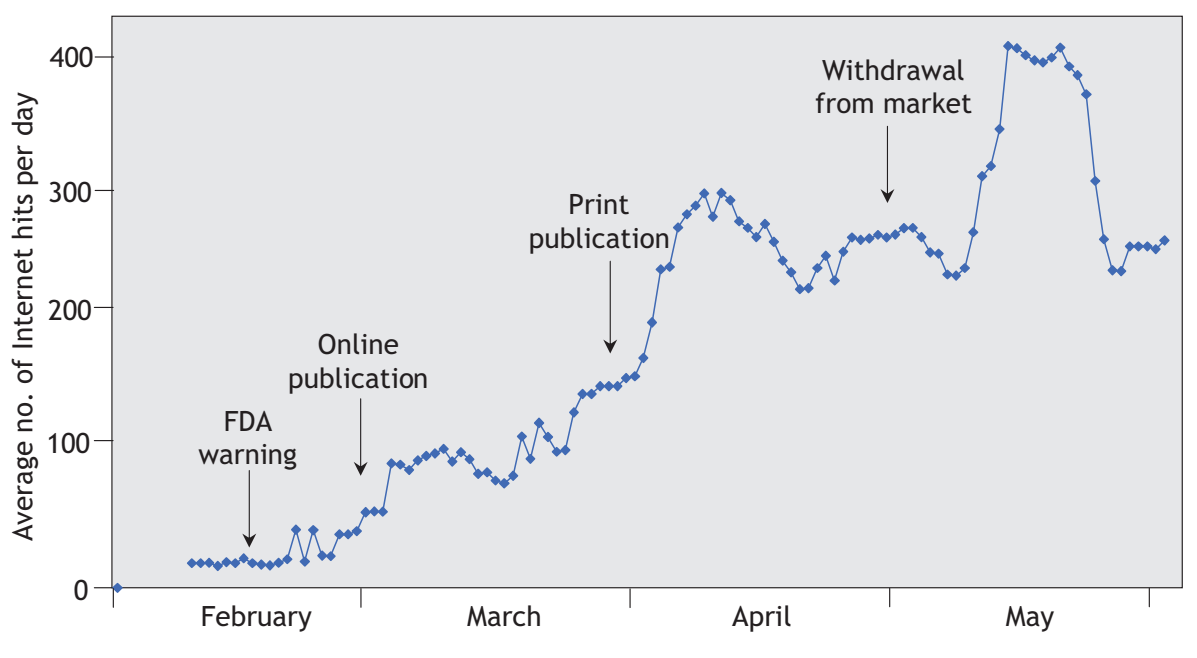

Figure 1: Average number of medicolegal Internet hits before and after publication of an article in the New England Journal of Medicine about the adverse events associated with gatifloxacin.

warning issued by the manufacturer and the US Food and Drug Administraion.

Within a week of the article's early release, about roo Internet hits were identified each day. This number increased to more than 300 hits within I week of full publication in print. Following a transient decline, the manufacturer's withdrawal of the drug was associated with an additional increase in the number of hits to about 400 per day. Within-rater agreement for observations throughout the study interval was excellent (intraclass correlation coefficient $-0.8 \mathrm{I} 4$ ).

To investigate the durability of this phenomenon, we repeated the search I year following the article's early release (Mar. I, 2007). At that time, we identified 522 websites that were soliciting personal-injury claimants.

\section{Interpretation}

We found that the publication of a study concerning the adverse drug events associated with gatifloxacin led to a rapid, dramatic and sustained increase in Internet-based solicitation for litigants for personal-injury claims. Because we had a baseline measure of Internet activity (i.e., the period before the article's early release), we were able to document the magnitude of the change in Internet-based medicolegal solicitation.

A detailed review of the contents of each identified website every day would have been prohibitive; however, we examined many of the websites on an informal and periodic basis. Most websites appeared to be for law firms in North America (mainly in the United States), possibly because we restricted our search to English-language websites. Many sites offered representation for a wide array of drug- and device-related lawsuits (e.g., Vioxx, Accutane, Paxil, Ortho-Evra), and the websites invited prospective claimants to submit details of their cases online.

Some limitations of this study deserve mention. Although our search strategy was chosen for its specificity, it is possible that some hits did not reflect solicitation of personal-injury claimants. In addition, some hits may have represented duplicate links to the same group of attorneys, and the number of websites that were not identified by this strategy is unknown. The period of baseline Internet activity before the article's online release was relatively short (20 days) as a result of the expedited publication process. However, this is of little consequence given the magnitude of the change in Internet activity and because we did not use the baseline period to generate statistical inferences.

In conclusion, we found that publication of an article in a general medical journal can dramatically influence Internetbased solicitation of litigants for personal-injury claims.

This article has been peer reviewed.

Competing interests: David Juurlink taught a continuing medical education lecture on drug interactions for Bristol-Myers Squibb in 2005. Content of the lecture was the author's own.

Contributors: David Juurlink conceived the project and drafted the manuscript. All of the authors contributed to the design of the project, data collection and revision of the manuscript for important intellectual content. All of the authors gave approval of the final version for publication. David Juurlink assumes responsibility for the manuscript as a whole.

Acknowledgements: We thank Alex Kiss PhD for statistical advice.

David Juurlink and Moira Kapral are supported by New Investigator Awards and Laura Park-Wyllie is supported by a Postdoctoral Fellowship from the Canadian Institutes for Health Research.

\section{REFERENCES}

I. Berenson A. Merck inquiry backs conduct over Vioxx. The New York Times 2006 Sept 7. Available: www.nytimes.com/2006/o9/o7/business/o7merck.html?ex $=$ II8982880o\&en $=547$ fer 7 ac5544576\&ei=5070 (accessed 2007 Oct I2).

2. District of Columbia Bar. Soliciting plaintiffs for class action lawsuits or obtaining legal work through Internet-based Web pages. Washington: The Bar; 2007. Available: www.dcbar.org/for_lawyers/ethics/legal_ethics/opinions/opinion302.cfm (accessed 2007 Sept I3).

3. Juurlink DN, Mamdani MM, Lee DS, et al. Rates of hyperkalemia after publication of the randomized aldactone evaluation study. N Engl J Med 2004;35I:543-5I.

4. Park-Wyllie LY, Juurlink DN, Kopp A, et al. Outpatient gatifloxacin therapy and dysglycemia in older adults. N Engl J Med 2006;354:1352-6r.

Correspondence to: Dr. David N. Juurlink, Sunnybrook Health Sciences Centre, G Wing 106, 2075 Bayview Ave., Toronto ON M4N 3M5; fax: 4I6 480-6048; dnj@ices.on.ca 